\title{
Applying Learning Technologies In An Open Learning Context
}

Michael C. Cant, University of South Africa, South Africa

Cornelius H. Bothma, University of South Africa, South Africa

\begin{abstract}
The use of learning technologies are becoming more and more important in education. Not only is it essential that educational institutions look at new ways of learning and teaching, but they also need to adapt to the changing profile of their students and their learning habits. In this respect the use of technology has become important to both residential universities and Open learning institutions. It is the management of these technologies that are posing challenges to academia all over the world. Previous research undertaken by the authors in a specific department believed a learning management system to be the most appropriate technology to use. The experience of the head of department has however shown that lecturers are using the university's proprietary learning management system, myUnisa, either to a limited extent or hardly at all. Consequently, further research was undertaken targeting the other Chairs of Departments and selected senior lecturers within the School of Management Sciences, to which the Department of Marketing and Retail Management belongs, in order to identify ways of increasing the use of myUnisa amongst lecturers.
\end{abstract}

Keywords: Myunisa; Learning Technologies; Open Learning; Higher Education Institutions

\section{INTRODUCTION}

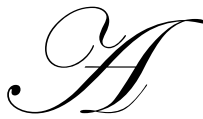

ccording to Glenn (2008) more and more universities globally are enlisting the use of a variety of learning technologies to support their teaching activities. These technologies are many and varied and include, amongst others, learning management systems (Monsakul 2007), e-mail (Collis and Van der Wende 2002), compact discs (CDs) and digital video discs (DVDs) (Klaasen 2001), mobile wireless technologies (Kim, Mims and Holmes 2006), video conferencing (Baltaci-Goktalay and Ocak 2006), social media (Hoffman 2009), as well as podcasting and instant messaging (Hamid Chang and Kurnia 2009).

Learning technologies have been used by many institutions worldwide and the University of South Africa (Unisa), a distance-learning institution and one of the world's largest 'mega universities' with a population of approximately 250000 students (UNESCO 2005), is no exception. In fact Unisa is placing more and more emphasis on technology in an effort to increase its reach and learning experience. These efforts however, though supported and initiated by management are not always adopted uniformly throughout the various colleges and academic departments within Unisa.

Some lecturers may be technologically challenged and steer away from technology, while others may use technologies not supported by the university. The varying influence that lecturers have on the use of technologies to support learning is not unique to Unisa and several authors have reported on this in their own respective contexts (Bakioglu and Hacifazlioglu 2007; Baltaci-Goktalay and Ocak 2006; Klassen 2001; Knipe and Lee 2002; Kollis and Van der Wende 2002; Monsakul 2007).

The challenge therefore lies in how these various academic departments within Unisa manage the lecturers' use of learning technologies within their respective departments. The CoD of the Department of Marketing and Retail Management (DMRM), faced with this challenge decided to undertake research to better understand the views of lecturers within the DMRM as to which learning technologies they felt were best to use to support the 
department's students. The main finding of this research was that a learning management system (LMS) is viewed by lecturers as the most appropriate technology to use.

A limitation of the research outlined above is that it does not adequately address the way forward for the $\mathrm{CoD}$ of the DMRM; it provides no clear procedure or guidelines for the adoption of an LMS within the department. The varying uptake by various lecturers of technologies to support learning is not unique to Unisa and several authors have reported on this in their own respective contexts (Bakioglu and Hacifazlioglu 2007; Baltaci-Goktalay and Ocak 2006; Klassen 2001; Knipe and Lee 2002; Kollis and Van der Wende 2002; Monsakul 2007). For example, Bakioglu and Hacifazlioglu (2004) refer to the "addiction or resistance ..." to technology amongst faculty, while Baltaci-Goktalay and Ocak (2006) similarly refer to faculty, some of whom "will accept new ways to teach with technology while others resist". The previous research by the authors and the findings of other authors together highlight the apparent anomaly that exists, namely that while there may be a belief amongst lecturers about the appropriateness of one or more learning technologies for teaching (in this case, an LMS), the practice amongst lecturers may be very different (reflected in their lack of use of myUnisa within the DMRM). There is thus a need to identify ways of encouraging lecturers to use myUnisa more actively; in other words, to turn their belief of the appropriateness of an LMS into practice.

Due to the above limitations and shortcomings, further research was subsequently undertaken amongst the CoDs within the School of Management Sciences as well as amongst lecturers within the department in order to build on the findings of the earlier research. Using a survey instrument and personal interviews, the respondents were asked to consider the earlier findings and to suggest ways of facilitating the adoption of an LMS within the department. Their responses provided useful input which was used to develop a framework to facilitate the adoption of an LMS within the department. The rest of the article summarises the earlier research, describes the methodology followed in terms of the current research, outlines the findings, and proposes a framework for the implementation of learning technologies within the DMRM (or any other academic department).

\section{OVERVIEW OF PREVIOUS RESEARCH}

Initial research undertaken by the authors attempted to determine the views of all lecturers within a specific department on these issues. The article reports that the Delphi method was used to gather the data over several interventions as it was felt that the iterative nature of the Delphi method would prove effective in ensuring that each lecturer would have an opportunity to contribute to the overall decision-making in selecting the most appropriate learning technologies for the DMRM to use.

In the article it was indicated that the research process followed in the gathering of data comprised the following six steps:

- $\quad$ Step 1: The respondents were requested to identify at least five learning technologies that they believed would be appropriate to improve the learning offerings of the department within the distance-learning context. They were also asked to identify the major challenges of implementing these technologies, as well as to suggest what might be done to address any of the challenges identified.

- Step 2: A single table was constructed from the responses received from respondents.

- $\quad$ Step 3: This single table was then re-sent to all the lecturers, asking them to 'fill the gaps', especially where no challenges had been identified or where they felt there may be some shortcomings or misunderstandings. They could add additional technologies not yet identified if they so wished. Once again, the answers were synthesised into a single table. A shortened list highlighting just the technologies without any additional explanation is attached as Addendum A.

- $\quad$ Step 4: Based on the feedback received the various technologies identified by the lecturers (25 in total) were listed in the form of a checklist. The respondents were then asked to identify their preferences for the 10 most relevant technologies. A frequency table was subsequently created and the 10 most relevant technologies were then indicated.

- $\quad$ Step 5: The responses were gathered and a revised list of the 10 most appropriate technologies was presented to respondents. The respondents were then asked to prioritise the list from 1 to 10 , with 1 being the most appropriate and 10 being the least appropriate. The responses were again used to develop a new 
list based on the mean score for the priorities indicated for each technology across all of the lecturers concerned. From this revised and prioritised list, the five most relevant learning technologies from the viewpoint of the lecturers were then identified. Table 1 outlines the findings from steps 3 to 5 . The five technologies were then brought together with the challenges that the lecturers had originally identified in steps 1 to 3 for each of these technologies. This list is outlined in Addendum B.

- $\quad$ Step 6: In the final instance the respondents were asked to compare the five technologies with each other in a pairwise fashion. This exercise resulted in 10 separate comparisons. In each pairwise comparison, the lecturer was asked to allocate a score of ' 1 ' to the technology that they regarded as the most appropriate of the two, and ' 0 ' allocated to the least appropriate technology. In the case where both technologies were considered equally appropriate, a score of ' 0 ' was allocated to both. This input was then transposed into a data table and analysed statistically using the Chi-square method. The purpose of the Chi-square analysis is to determine whether the observed frequencies (i.e. counts for the individual technologies selected by lecturers) differ markedly from what one would expect by chance (Anon. 2009). Table 2 below outlines the results obtained from the Chi-square analysis.

Table 1. Ranking and weightings of the top 10 learning technologies ${ }^{1}$.

\begin{tabular}{|c|l|c|}
\hline Overall rank & \multicolumn{1}{|c|}{ Proposed technology } & Mean ranking $^{\mathbf{2}}$ \\
\hline $\mathbf{1}$ & Learning management system (LMS) & $\mathbf{1 . 9}$ \\
$\mathbf{2}$ & Compact disc/digital video disc technologies (CD/DVD) & $\mathbf{5 . 0}$ \\
$\mathbf{3}$ & Email (EMAIL) & $\mathbf{5 . 6}$ \\
$\mathbf{4}$ & Web-based learning sites (WEB) & $\mathbf{5 . 7}$ \\
$\mathbf{5}$ & Automated telephone self-help services & (AUTO/TEL) \\
6 & Simple Messaging Service (SMS) / & 5.8 \\
7 & Multimedia Messaging Service (MMS) & 6.0 \\
8 & Satellite/video/teleconferencing & 6.0 \\
9 & Online discussion classes & 6.1 \\
10 & Webinars/podcasting & 7.2 \\
\hline
\end{tabular}

1. The technologies in bold represent the five technologies selected for further analysis using the chi-square method.

2. $\quad$ Lower values $=$ 'more appropriate', while higher values $=$ 'less appropriate' technologies.

3. It is not clear what lecturers envisaged this technology would include

4. This technology refers to those telephone services, which guide callers through a series of questions to find the most appropriate assistance (this could also include interactive voice response systems).

Table 2. Chi-square test statistics.

\begin{tabular}{|c|c|c|c|c|c|}
\hline & CD/DVD & AUTO/TEL & WEB & EMAIL & LMS \\
\hline $\begin{array}{c}\text { Chi-square } \\
\left(\mathbf{X}_{\text {calc }}^{\mathbf{2}}\right)\end{array}$ & 3.769 & 2.769 & 0.308 & 13.000 & 9.308 \\
$\mathbf{d f}$ & 1 & 1 & 1 & 1 & 1 \\
Asymptotic value & 0.052 & 0.096 & 0.579 & 0.000 & 0.002 \\
Residual & -7.0 & -6.0 & -2.0 & -13.0 & 11.0 \\
\hline
\end{tabular}

The findings outlined in the article highlighted the importance of an LMS as the technology of choice according to lecturers within the DMRM. This was considered not to be surprising as Unisa already has an excellent proprietary LMS in place called myUnisa. This is a powerful online tool that is available to all registered students, and lecturers at Unisa will have had to use it from time to time in order to execute certain required tasks. 
The other technologies making up the top five technologies list as selected by the lecturers, included CD/DVD technologies, automated telephone self-help services, email, and web-based learning sites.

\section{LOOKING AHEAD}

A major short coming of the initial research was that it provided no direction for the $\mathrm{CoD}$ as to how to go about encouraging the use of a learning management system such as the Unisa LMS, namely myUnisa. An in depth analysis of the use of myUnisa by staff members have revealed that lecturers hardly use myUnisa, and if they do, only to a limited extend. It became very clear from these findings that lecturers are aware that a LMS can be effective in supporting students in their learning activities, but these same lecturers do not effectively use myUnisa in their teaching activities. The question that subsequently arose was how this situation could be turned around. It is this question that gave rise to this further research.

\section{METHODOLOGY}

It was decided to expand on the previous quantitative research by using a qualitative method involving personal interviews with the CoDs of the School of Management Sciences (SMS). In addition, an additional seven personal interviews were also conducted with selected senior lecturers within the school to ascertain their thinking as to how the $\mathrm{CoD}$ might go about increasing the use of myUnisa amongst lecturers. The total sample thus comprised 13 respondents.

The selection of these respondents were based on the following assumptions. Firstly, it was assumed that all CoD's in the SMS faced similar challenges in the use of the LSM. Secondly, the methods used to encourage lecturers to use the LMS was assumed to be similar between departments. Thirdly, it was deemed appropriate to include the lecturers themselves and to obtain their views on how the $\mathrm{CoD}$ might be able to change the current practice within the department and to increase the lecturers' use of myUnisa.

To this end, a single survey instrument was created (see addendum C). The survey instrument provided an introduction to the research by summarising the research that had gone before and posing four open-ended questions and one closed-ended question for respondents to answer. These questions addressed the issues outlined in the previous paragraph. Their answers were recorded for later analysis.

\section{MAJOR FINDINGS OF THE RESEARCH}

The main findings associated with each of the questions are given below. These answers were not the only ones received but can be regarded as major findings.

Question 1: In your opinion, is an LMS (such as myUnisa) the most appropriate learning technology to use to support the teaching activities in your department?

It was agreed by all the respondents that the most appropriate technology to use was an LMS system.

Question 2: In your opinion, are the lecturing staff in your department currently using myUnisa in their teaching activities?

The responses to this question was very interesting and worrying as the overwhelming majority of respondents $(92,3 \%)$ indicated that it was their view that lecturers used myUnisa either to a limited extent or hardly at all.

Question 3: If you believe that your colleagues in your department are using myUnisa either to a limited extent or hardly at all, what do you think the reason for this is? 
A number of replies to this question was found and can be grouped as follows:

Fear in the use of technology/limited exposure and understanding of technology

From the comments given by respondents it would seem that lecturers are fearsome in the use of technology due to a lack of knowledge, or incapable of using the technology. This observation is based on typical responses such as "they are not familiar with how the system works", "they have a natural resistance to technology due to underexposure", "many are set in their ways and do not want to embrace new concepts and ideas". Some of the respondents reported that lecturers were not aware of the full capabilities of the technology. This view is supported by statements such as "Some of the lecturers are still unsure about the full application of myUnisa", and "Most see it as a passive webpage to upload study material and tutorial letters".

\section{Practical on hands exposure to myUnisa is lacking}

A general reference was made to the fact that staff have not been adequately trained in the use of myUnisa even though training sessions have been available for a considerable period of time. This unwillingness to undergo training may be a result of a fear for technology or even failure! Using an excuse of not having had training may therefore only be an escape route and not the true reason.

Shortage of time available to use myUnisa

An excuse used very often by academics worldwide is "a shortage of time'. In some cases it is justified and others less so. Respondents indicated that a potential problem is that lecturers do not have sufficient time to spend on myUnisa. Comments supporting this assertion include "Lecturers may have time constraints", and "it takes up a lot of available time to interface on a LMS". A careful analysis of lecturers time may shed some light on this observations correctness or validity.

Lecturers see no value in myUnisa

One of the respondents commented on the fact that "Some of the lecturers do not see the importance or value of using myUnisa." At the same time, other respondents commented that there was "Limited interaction from students for the smaller modules" and that the use of myUnisa by students "... varies depending on the nature and size of modules."

Question 4: How would you encourage the use of myUnisa within your department?

A number of suggestions were received from respondents which was regarded as suitable to encourage the use of myUnisa.

In the first instance it was made clear that if learning technologies were to be used in an ODL institution there must be buy in from all concerned. This includes lecturing staff as well as students. This is a two way communication method and must be accepted by both parties. This will require that students are instructed in the use and benefits of the myUnisa system, and that lecturing staff are equipped to use the system and to use it on a regular basis. In order to achieve this, the following was proposed by the respondents:

Ensure that all lecturers undergo training on myUnisa

Make the use of myUnisa a key performance area

Establish a mentoring programme within each department

Plan and manage the use of myUnisa within each department

Highlight the benefits of myUnisa for lecturers 
Question 5: What should the $\mathrm{CoD}$ do about the other learning technologies identified by lecturers (other than the LMS)?

Various replies were received to this question. The more appropriate ones are listed below:

More research in the use of technologies in an ODL context is needed.

Due to the nature of an ODL institution and the unique challenges the students and the lecturers face, careful consideration of applicable technologies is needed. In order to identify and use the best technologies in an ODL context, respondents indicated that more intensive and directed research be undertaken to establish the suitability of different learning technologies to support the teaching activities. It was also suggested that as many as possible technologies be evaluated and researched in order to establish what is viable to use.

\section{Support innovative thinking}

In order to support learning technologies in an ODL context innovative thinking is required and lecturers must think "out of the box". Respondents made it clear that it is the responsibility of the CoD to encourage innovativeness and creative thinking amongst staff and students in order to maximise the range and effectiveness of learning technologies. The ODL lecturer has many opportunities to experiment with subjects and to test the responses to a new initiative - without any real harm that can be done.

\section{DISCUSSION}

The abovementioned findings provide some direction for each CoD to follow in order to increase the use of myUnisa within their respective departments. To begin with, the findings associated with Question 1 highlight the convergence of the views of lecturers and CoDs supporting the adoption of myUnisa as the learning technology of choice within departments. The findings associated with Question 2 also support the initial assertion made about the lack of adoption of myUnisa amongst lecturers within the various departments - other CoDs have had the same experience. When brought together, these findings also support the view that a 'disconnect' exists between what lecturers believe is an important learning technology and their day-to-day practices (reflected in the relatively low usage of myUnisa amongst lecturers).

\section{Increasing the use of myUnisa amongst lecturers}

The findings associated with Questions 3 and 4 provide insight that enables one to make certain proposals that can be used to direct the efforts of CoDs to increase lecturers' use of myUnisa. These proposals are highlighted below. To begin with, it would seem that the reason for the low use of myUnisa by lecturers can be ascribed to the lack of exposure, training and time.

As far as exposure is concerned, if lecturers are not using myUnisa, then their exposure to the technology and its benefits will be limited as a consequence. In order to increase myUnisa usage, the university has already issued an instruction to the effect that all lecturers should meet minimum usage levels for the year. As a result, myUnisa usage is increasingly being incorporated by CoDs as a measurable target into each lecturer's performance agreement. It would seem that this approach has had some impact as usage by lecturers of myUnisa in the first three months of 2010 (Anon 2010) has matched lecturer usage of the system for the whole of 2009. But CoD's can also have some influence in this regard. They can compel lecturers to use myUnisa by making usage targets part of each lecturer's performance agreement. They can also encourage use by providing training, arranging mentors, and promoting the benefits of myUnisa. These alternatives are discussed below.

One of the ways of increasing exposure and usage is through training. It is argued that further training is a key component in increasing the usage of myUnisa by lecturers. Some lecturers argue that they cannot use myUnisa because they do not know how. The obvious solution is to encourage or even compel lecturers to do myUnisa training. This training should also be structured in such a way that it takes the participant through several levels of use (from beginner to more advanced user). This training can be scheduled over a longer period of time to ensure 
that the lecturer receives regular training during the course of the year. It might be worthwhile also to make the training a requirement of the lecturer's performance agreement to ensure that such training interventions are measured

Lack of time is another real problem. Lecturers are facing increased pressure in the form of greater teaching and research demands, as well as an ever-increasing administrative workload. Using myUnisa more, will require additional time and this is perhaps one of the lecturers' major concerns with 'becoming involved'. Anecdotal evidence from lecturers that are 'champions' of myUnisa is that it is time consuming; time spent on myUnisa translates into lost opportunities elsewhere such as less time to do research. To address this situation, it is proposed that myUnisa involvement be made a key performance area. Doing so will enable lecturers to plan for their involvement in myUnisa by agreeing to sacrifice other duties in order to spend more time on myUnisa..

Fear of technology is another problem that some lecturers face. There are still lecturers that struggle to work with everyday programs such as MS Word, Powerpoint and Internet Explorer. Getting these lecturers to interact with an online LMS such as myUnisa is thus a major obstacle. It is proposed that these lecturers will need training, exposure, mentoring and some persuasion in order to use myUnisa. These lecturers will also need to be managed more carefully.

There will also be some lecturers that see no value in myUnisa. They will argue that the way they have been teaching over the past number of years is adequate and requires no change. They will inevitably identify problems with myUnisa, as well as reasons why one should not use myUnisa. Changing the views of these types of lecturers can be achieved either by compelling them to use myUnisa or encouraging them to use myUnisa. In this last-mentioned regard it might be worthwhile highlighting the benefits of the facility and sharing success stories with the lecturer concerned.

The respondents also suggested several additional ways in which myUnisa use could be increased. Amongst others, it was recommended that a myUnisa 'champion' be identified within a department. It would be this individual's task to promote myUnisa amongst colleagues, sharing benefits and success stories with them, as well as providing them with hints and tips to improve usage.

Besides for the myUnisa 'champion', the respondents recommended that lecturers - especially the more technology illiterate lecturers - be mentored in their use of myUnisa. The more experienced myUnisa users in the department could be asked to assist in mentoring one or more of their colleagues. This would require a bit more time and effort on their part especially in the beginning, but over time this will fall away.

Respondents also suggested focusing on the benefits of the system. If lecturers begin to realise what the system can do for them, they may be more willing to adopt it. Highlighting myUnisa's benefits and success stories should be one of the primary tasks of the myUnisa champion as well as of the mentors within the department.

Finally, the respondents highlighted the importance of planning and managing myUnisa usage, placing this responsibility on the shoulders of the CoD. This management responsibility would focus on negotiating myUnisa usage performance targets per lecturer and ensuring that these targets are met, ensuring that lecturers are given the time for and actually attended myUnisa training, overseeing the integration of myUnisa tools with the department's study materials, and promoting myUnisa usage amongst lecturers..

Figure 1 below provides a framework that CoDs can use to increase the use of myUnisa within their respective departments. This framework highlights five areas of focus discussed above, namely training, exposure, mentoring, promotion and persuasion. It highlights the role of the champion and the need for management. What is more it suggests that the use of myUnisa can be increased either through the efforts of the department (push) or by encouraging greater use of myUnisa by students (pull). If there is greater involvement of students in myUnisa, this may compel lecturers also to be more involved. 


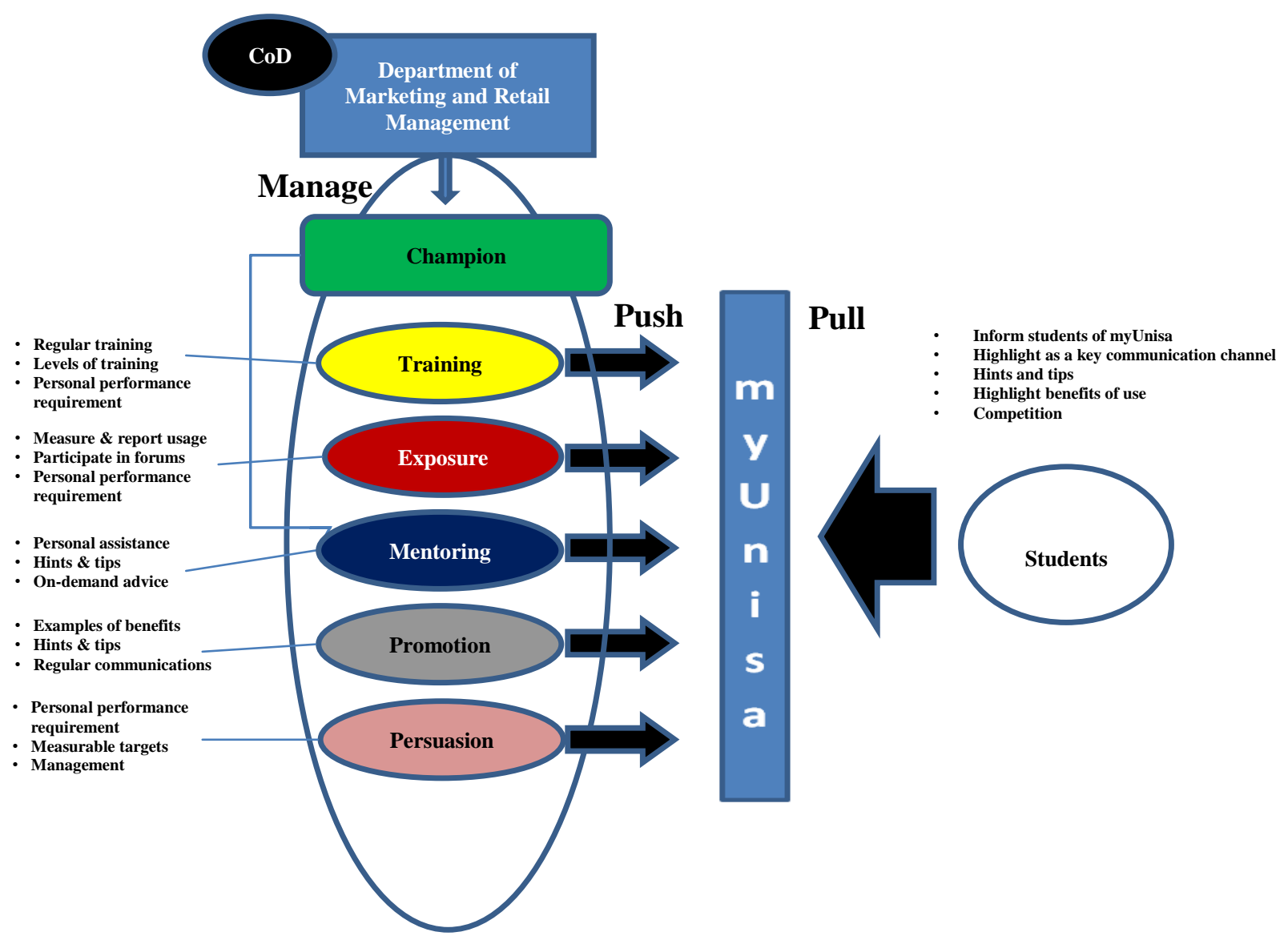

Figure 1. Proposed framework to facilitate increased use of myUnisa.

\section{Other learning technologies}

As far as other learning technologies are concerned, the overwhelming response was that such alternative technologies should first be fully research and evaluated before they are adopted by the department. In addition, it was suggested that the $\mathrm{CoD}$ should encourage lecturers to experiment with alternative technologies and where such technologies are found to be useful, they can then be considered for adoption by the department.

\section{CONCLUSION}

The lecturers interviewed overwhelmingly supported the use of an LMS as their preferred technology of choice. This is a very interesting finding. Unisa has an excellent bespoke LMS in place called myUnisa (Unisa Learning Management System, 2009). It is a powerful online tool that is available to all registered students. The interesting fact is that most lecturers within the DMRM do not use myUnisa. The findings thus suggest that although lecturers are reluctant, unwilling or unable to use an LMS, they do appear to recognise the value that it brings to learning and as a means of supporting the student.

The findings might also mean that myUnisa is all that lecturers are familiar with (within their academic sphere) and their selection of an LMS as the preferred learning technology of choice is based on this familiarity. It could also mean that because the University has been pressing for the use of the LMS amongst academics lecturers feel obliged to recommend its use. 
It is also interesting to note that web-based learning also appeared in the list of top five technology choices. Bearing in mind that the myUnisa LMS is essentially a web-based learning system, there is arguably a serious overlap between these two choices. This supports the view that lecturers consider the web (or the idea of 'online learning' as embodied in an LMS) as the route to go.

Another suggestion might be that lecturers feel that students are facing a medium-overload (i.e. the use of too many technology channels), which might impact on the effectiveness of many of these technologies, especially if they are used separately. An LMS, on the other hand, has the potential to incorporate many if not most of these technologies (such as webinars, blogs, email, SMS, discussion forums, etc.) into a single interface or online environment and could therefore serve as 'home' or 'base' for many of the other suggested technologies. This would make it a 'one-stop shop' of choice.

\section{AUTHOR INFORMATION}

Michael C. Cant - Professor in Marketing and Retail and an active consultant for 30 years in small business. Contact details: E-mail: cantmc@unisa.ac.za, Phone: +27 12429 4456. Research interests: small business, learning technologies and distance education.

Cornelius M. Bothma - Senior lecturer in Marketing and Retail. Contact details: E-mail: bothmch@unisa.ac.za. Phone: +27 12429 4376. Research interests: international marketing and trade, social media and technology in learning.

\section{REFERENCES}

1. Anon. 2009. Chi-square test. StatPac. Available at http://www.statpac.com/statistics-calculator/counts.htm. Accessed on April 13, 2009.

2. Bakioglu, A. and O. Hacifazlioglu. 2007. Lecturers' and students' attitudes towards the use of technology in lecturers: No taboos, more thinking. Paper presented at the ISATT 2007, Conference, July 5-9, in Ontario, Canada.

3. Baltaci-Goktalay, S. and M. A. Ocak. 2006. Faculty adoption of online technology in higher education. Turkish Online Journal of Educational Technology in Higher Education 6, no. 4: first and last page of article.

4. Collis, B. and M. C. van der Wende. 2002. Models of technology and change in higher education: An international comparative survey on the current and future use of ICT in higher education. Enschede, the Netherlands: Center for Higher Education Policy Studies.

5. Gelnn, M. (2008). The future of higher education: How technology will shape learning. A report from the Economist Intelligence Unit, London United Kingdom.

6. Hamid, S., S. Chang and S. Kurnia. 2009. Identifying the use of online social networking in higher education. Paper presented at the ASCILITE 2009 Conference, December 6-9, in Auckland, New Zealand.

7. Hoffman, E. S. 2009. Evaluating social networking tools for distance learning. Paper presented at the Technology, Colleges and Community (TCC) Worldwide Online Conference 2009, April 14-16, at the University of Hawaii, in Hawaii, United States of America.

8. Kim, S. H., C. Mims and K. P. Holmes. 2006. An introduction to current trends and benefits of moile wireless technology use in higher education. AACE Journal (Association for the Advancement of Computing in Education) 14, no. 1: 77-100.

9. Klassen, J. 2001. Pedagogical support for use of information technology in teaching. Informing Science (June): 301--309.

10. Knight, S. 2009. Effective practice in a digital age: A guide to technology-enhanced learning and teaching. Joint Information Systems Committee report, Bristol, United Kingdom. Available at http://www.jisc.ac.uk/media/documents/publications/effectivepracticedigitalage.pdf. Accessed on April 12, 2009.

11. Knipe, D. and M. Lee. 2002. The quality of teaching and learning via video conferencing. British Journal of Educational Technology 33, no. 3: 301-311. 
12. Marginson, S. 2006. Dynamics of national and global competition in higher education. Journal of Higher Education 52: 1-39.

13. Monsakul, J. 2007. Learning management systems in higher education: A review from faculty perspective. Paper presented at the Fourth International Conference on eLearning for Knowledge-Based Society, November 18-19, in Bangkok, Thailand.

14. Rogers, G. 2004. History, learning technology and student achievement: Making the difference? Active Learning in Higher Education 5, no. 2: 232-247.

15. Schwab, J. 2004. Social work statistics: Chi-square test of independence. Class notes. School of Social Work, University of Texas, Texas, United States of America.

16. Steyn, A. G. W., C. F. Smit, S. H. C. du Toit and C. Strasheim. 2003. Modern statistics in practice. Pretoria: Van Schaik.

17. Thangaratinam, S. and C. W. E. Redman. 2005. The Delphi technique. The Obstetrician \& Gynaecologist 7: $120-125$.

18. Turney, C. S. M., D. Robinson, M. Lee and A. Soutar. 2009. Using technology to direct learning in higher education: The way forward? Active Learning in Higher Education 10, no. 1: 71-83. 